\title{
СТЕНОБИОНТНЫЕ НАСЕКОМЫЕ (НА ПРИМЕРЕ ЖУКОВ-ЛИСТОЕДОВ - COLEOPTЕRA: CHRYSOMELIDAE) КАК ИНДИКАТОРЫ СОСТОЯНИЯ ОКРУЖАЮЩЕЙ СРЕДЫ
}

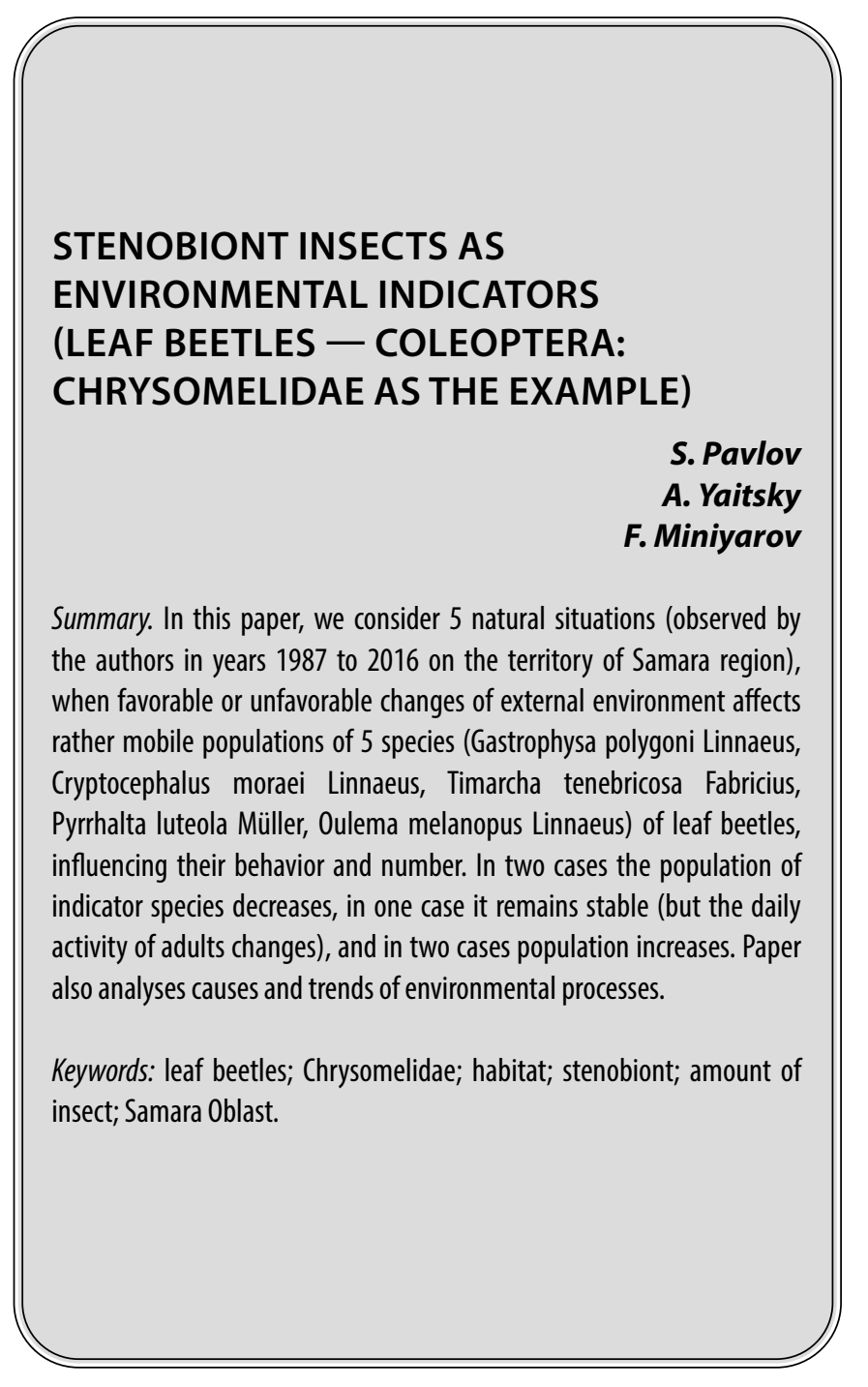

\section{Введение}

$\mathbf{0}$ кружающая (внешняя) среда оптимизирует обитание профильных для нее видов. Изменение привычной среды корректирует условия обитания всех компонентов сообщества, провоцируя их либо к бурному развитию, либо к активному вымиранию, либо к частным адаптациям к меняющимся условиям среды.

По нашим данным, из 286 видов жуков-листоедов Самарской области 95 - редко встречающиеся, а 28 (относящихся к наземным биотопам) - стенобионтны (т.е.
Павлов Сергей Иванович

К.б.н., дочент, ФГБОУ ВО «Самарский государственный сочиально-педагогический университет» pavlov@sgspu.ru

Яицкий Андрей Степанович Старший преподаватель, ФГБОУ ВО «Самарский государственный сочиально-педагогический университет» yaitsky@sgspu.ru Минияров Фарит Талгатович К.б.н., дочент, ФГБОУ ВО «Астраханский государственный университет» fminiyarov@mail.ru

Аннотация. В предлагаемой работе рассмотрено 5 закономерных природных ситуаций (наблюдаемых авторами в 1987-2016 гг. на территории Самарской области), когда меняющаяся (в благоприятную или неблагоприятную сторону) внешняя среда воздействует на, более или менее, мобильные популяции 5 видов жуков-листоедов (Gastrophysa polygoni Linnaeus, Cryptocephalus moraei Linnaeus, Timarcha tenebricosa Fabricius, Pyrrhalta luteola Müller, Oulema melanopus Linnaeus), влияя на их поведение и численность. В двух вариантах случаев население видов-индикаторов сокращается, в одном - остается стабильным (но меняется режим суточной активности имаго), в двух случаях - увеличивается. Анализируются также причины и тенденции экологических процессов.

Ключевые слова: жуки-листоеды; Chrysomelidae; условия обитания; экологические условия; стенобионтные насекомые; численность насекомых; Самарская область. 
представленных видов (стенобионтных и фоновых, местами редких).

Стенобионтные виды жуков - более многочисленные в природе, но малопластичные, «запрограммированные» на рамки каких-то конкретных условий (более чуткие к изменениям этих рамок). Стенобионтность вида может быть связана со следующими причинами:

1. со спектром и запасами имеющихся кормовых растений;

2. с тяготением насекомого к конкретному типу биотопа;

3. с его терпимостью к микроклиматическим режимам среды в целом или к их отдельным (избранным) параметрам;

4. с преференциями в сочетании фенологических фаз и природной среды биотопа, и ее экологических условий в определенный период времени.

Все это делает стенобионтные виды, «зажатые» в довольно узких границах определенных экологических условий, вполне надежными для мониторинга видами-индикаторами.

Общеизвестно, что окружающая среда по разным причинам постоянно изменяется. Агентами, влияющими на ее трансформацию, являются абиотические, биотические и антропогенные факторы. Любой из них либо может действовать отдельно, либо все факторы способны «работать» в комплексе (причем, часто с противоположным вектором: один - улучшает условия обитания, а другой - осложняет их).

Постепенная трансформация (тем более, резкая «ломка» условий) среды в первую очередь регистрируется ее отдельными, сильно зависимыми элементами (редкими и стенобионтными видами). Часто, еще до того, как бывает отмечено изменение самой среды (сложного комплекса величин), регистрируются случаи уменьшения (постепенного), сокращения (довольно заметного) или падения (существенного) поголовья индикаторных видов.

Отдельные аспекты взаимодействия окружающей среды и организма жуков-листоедов были, в разной степени, рассмотрены в работах разных авторов [1-6]. Мы же, в свою очередь, рассматриваем 5 реальных вариантов закономерных состояний воздействия трансформации среды на численность насекомых-фитофагов.

\section{Цель работы}

Анализ зарегистрированных нами вариантов закономерных ситуаций, когда внешние условия заметно корректируют численность перспективных для индика- ции динамики природных процессов видов насекомых (на примере Coleoptera: Chrysomelidae).

\section{Материал и методика исслеАования}

Нами было использовано 5 перспективных (достаточно редко встречающихся и в то же время заметных) видов (Gastrophysa polygoni Linnaeus, Cryptocephalus moraei Linnaeus, Timarcha tenebricosa Fabricius, Pyrrhalta luteola Müller, Oulema melanopus Linnaeus) жуков-листоедов (Coleoptera: Chrysomelidae).

Нами были применены следующие методы исследования:

учеты имаго на трансекте;

учеты на стационарных модельных площадках;

- анализ динамики численности жуков в зависимости от условий среды.

По поводу последнего метода существуют противоположные суждения: одни исследователи [7] считают его малоперспективным, другие [8-10] - вполне подходящим. Еще 30-35 лет назад нами было отмечено [11], что, независимо от причин деградации коренных местообитаний, вызывающих сокращение трофической базы, численность даже, казалось бы, местных фоновых видов листоедов чутко реагирует на возникший дефицит корма и заметно снижается.

Латинские наименования видов жуков приводятся по работе Ю. М. Зайцева, Л.Н. Медведева [12].

\section{Результаты исслеАования \\ и их обсужАение}

Ниже мы рассмотрим 5 наблюдавшихся нами в 19872016 гг. вариантов закономерностей, связанных с изменением поведения и численности жуков-листоедов, в результате преобразований состояния окружающей среды.

Закономерность 1. В условиях меняющейся среды (неблагоприятные условия перезимовки кормовых растений в результате малоснежья, последующий сухой летний сезон), когда площадь проективного покрытия фитоценоза Polygonum aviculare L. сократилась на 30\%, а площадь листовой пластинки - почти на $20 \%$ от среднестатистического размера, при стабильном положении изолированной популяции Gastrophysa polygoni (фоновый для европейской части России, местами редкий вид), численность жуков убывает в 4-5 раз.

Закономерность 2. При изменении условий внешней среды (негативные условия перезимовки кормовых растений в результате сильных морозов, крайне сухой 
последующий летний сезон), в поисках недостающего корма имаго Cryptocephalus moraei (редкий, местами фоновый для Самарской области вид, трофически связанный только с Hypericum perforatum L.) начинают перемещаться в радиусе 30-70 м вокруг границ прежнего местообитания (первоначально насекомые рассеиваются в пространстве), в итоге их численность сокращается, по меньшей мере, в 2 раза.

Закономерность 3. В условиях трансформирующейся среды (частые и обильные летние дожди, повышенная влажность воздуха, более прохладные условия обитания, чем в сухие сезоны), при стабильном положении изолированной популяции Timarcha tenebricosa в Caмарской области (редкий, реликтовый, малоподвижный и бескрылый вид, трофически связанный только с ксероморфной вариацией Galium verum L. [13]), численность жуков, если и убывавет, то не столь значительно, зато насекомые сменяют периоды суточной активности (сумеречную, утренне-вечернюю - на исключительно дневную), становясь очень заметными и местами даже многочисленными в дневной период (примерно с 11 до 16 часов).

Закономерность 4. В условиях меняющейся среды (благоприятные условия перезимовки 2004 г. кормовых растений - Ulmus laevis Pall. и Ulmus parvifolia Jacq., последующая теплая и влажная весна в год повышенной солнечной активности [14]), когда количество листьев на деревьях возросло примерно на 15\%, а площадь листовой пластинки - почти на $10 \%$ (от среднегодового показателя), при стабильном положении изолированной популяции (в границах г. Самары) Pyrrhalta luteola (фоновый, местами редкий вид), численность жуков резко увеличилась примерно в 6 раз (за 2 месяца ими было уничтожено до 40\% объема крон кормовых растений Ulmus laevis и Ulmus parvifolia).

Закономерность 5. В условиях меняющейся среды (последовательная активная вегетация растений
Triticum L. на пониженных и возвышенных участках поля в условиях короткой, теплой весны), когда площадь проективного покрытия агроценоза возрастает, расселение из мест зимовки жуков Oulema melanopus (фоновый, местами многочисленный, местами редкий вид для Самарской области) идет в 2 этапа:

1. на стадии «всходов-кущения» насекомые концентрируются на закрытых от ветра, более пониженных участках рельефа с загущенной растительностью;

2. на стадии «стеблевания» пшеницы происходит переселение имаго на более разреженные и лучше прогреваемые возвышенные пространства, где иногда группируется до 80-90\% всей популяции жуков данного вида.

Аналогичную ситуацию (локализацию очагами) наблюдала Е.В. Гуськова [15], после массового вылета перезимовавших жуков Oulema melanopus на поля.

\section{Зак^ючение}

Следует отметить, что, если объективно оценить поголовье редко встречающихся видов сразу затруднительно, то просчитать плотность не слишком многочисленных (но достаточно заметных) стенобионтных насекомых вполне возможно. Именно после регистрации их значительного убывания, следует обратить внимание на состояние популяции заведомо редких видов [16, с. 178], в результате чего можно сделать объективный вывод об определенной подвижке процессов деградации экологических условий, повлиявших на динамику численности видов-индикаторов.

Зная предельные рубежи оптимальных условий обитания индикаторных видов, имея возможность оценить колебания их численности (отклонение от нормы), можно отчетливо представить себе степень и причины трансформации внешней среды, а также перспективы возврата условий к оптимальному природному уровню.

\section{ЛИТЕРАТУРА}

1. Гуськова Е. В. Ареалогический анализ жуков-листоедов (Coleoptera, Chrysomelidae) Южного Урала // Энтомологические исследования в Северной Азии: мат-лы VII Межрегионального совещания энтомологов Сибири и Дальнего Востока в рамках Сибирской зоологической конференции. Новосибирск, 2024 сентября 2006 г. Новосибирск, 2006. С. 53-55.

2. Mahani M.K., Hatami B., Seyedoleslami H. Host preference of three elms and hackberry for elm leaf beetle, Xanthogaleruca (=Pyrrhalta) luteola (Coleoptera: (hrysomelidae) // Forest Ecology and Management. 2003. Vol. 186, № 1-3. P. 207-212.

3. Беньковский А. О. Жуки-листоеды европейской части России: дис. ... д-ра биол. наук: 03.02.05. М., 2011. 517 с.

4. Беньковский А.0., Орлова-Беньковская М. Я. Трофическая специализация жуков-листоедов (Coleoptera, Chrysomelidae) Приволжской возвышенности // Поволжский экологический журнал. 2014. № 2. С. 175-183.

5. Беньковский А.О., Орлова-Беньковская М. Я. Фауна жуков-листоедов (Coleoptera, Chrysomelidae) хвалынского Приволжья (Саратовская область) (все подсемейства, кроме Alticinae) // Бюллетень Московского общества испытателей природы. Отдел биологический. 2013. Т. 118, № 4. С. $15-20$.

6. Исаев А. Ю. Определитель жесткокрылых Среднего Поволжья. Ч. III. Polyphaga — Phytophaga. Ульяновск: Издательство «Вектор-С», 2007.256 с. 
7. Богачева Н. И. Антропогенные изменения членистоногих мезофауны почвы и подстилки в березовых редколесьях Нижнего Приобья // Фауна и экология насекомых Урала: межвуз. сб. науч. тр. / отв. ред. А. С. Уточкин. Пермь: ПГУ, 1993. С. 8-19.

8. Лапин Е.И., Израилевич С. В. Индикация техногенных загрязнений по фаунистическим комплексам жесткокрылых // Успехи энтомологии в СССР: мат-лы 10-го съезда Всесоюз. энтомол. об-ва, Ленинград, 11-15.09.1989. СПб.: ЗИН РАН, 1993. С. 37-38.

9. Хотько Э.И., Чумаков Л. С., Селявко Т. М. Функциональная структура населения жужелиц как показатель степени антропогенной нагрузки на экосистемы // Успехи энтомологии в СССР: мат-лы 10-го съезда всесоюз. энтомол. об-ва, Ленинград, 11-15.09.1989. СПб.: 3ИН РАН, 1993. С. 72-74.

10. Schneider K. Verteilungsmuster von Curculioniden (Coleoptera — Insecta) in einem Transekt unterschiedlich immissionsbelastetel Kieferrnforste der Dübener Heide // Hercynia. 1984. Vol. 21, № 2. P. 162-178.

11. Павлов С. И. Редкие виды жуков-листоедов Куйбышевской области и причины сокращения их численности // Охрана животных в Среднем Поволжье: межвуз. сб. науч. тр. Куйбышев: КГПИ, 1988. С. 51-56.

12. Зайцев Ю.М., Медведев Л. Н. Личинки жуков-листоедов России. М.: Товарищество науч. изд. КМК, 2009. 246 с.

13. Медведев Л.Н., Рогинская Е. Я. Каталог кормовых растений жуков-листоедов (Coleoptera, Chrysomelidae) фауны СССР. М.: ИЭМЭЖ им. А. Н. Северцова АН СССР, 1988. С. 49-66.

14. Шабалин И. М. Самарский лес. Самара: СКИ, 2005. 76 с.

15. Гуськова Е. В. Особенности биологии и экологии листоедов Oulema melanopus L. в условиях Южного Урала // Вестник Челябинского государственного педагогического университета. Сер. 10. Экология. Валеология. Педагогическая психология. 2003. № 4. С. 49-59.

16. Чернов Ю. И. Природная зональность и животный мир суши. М.: Мысль, 1975. 222 с.

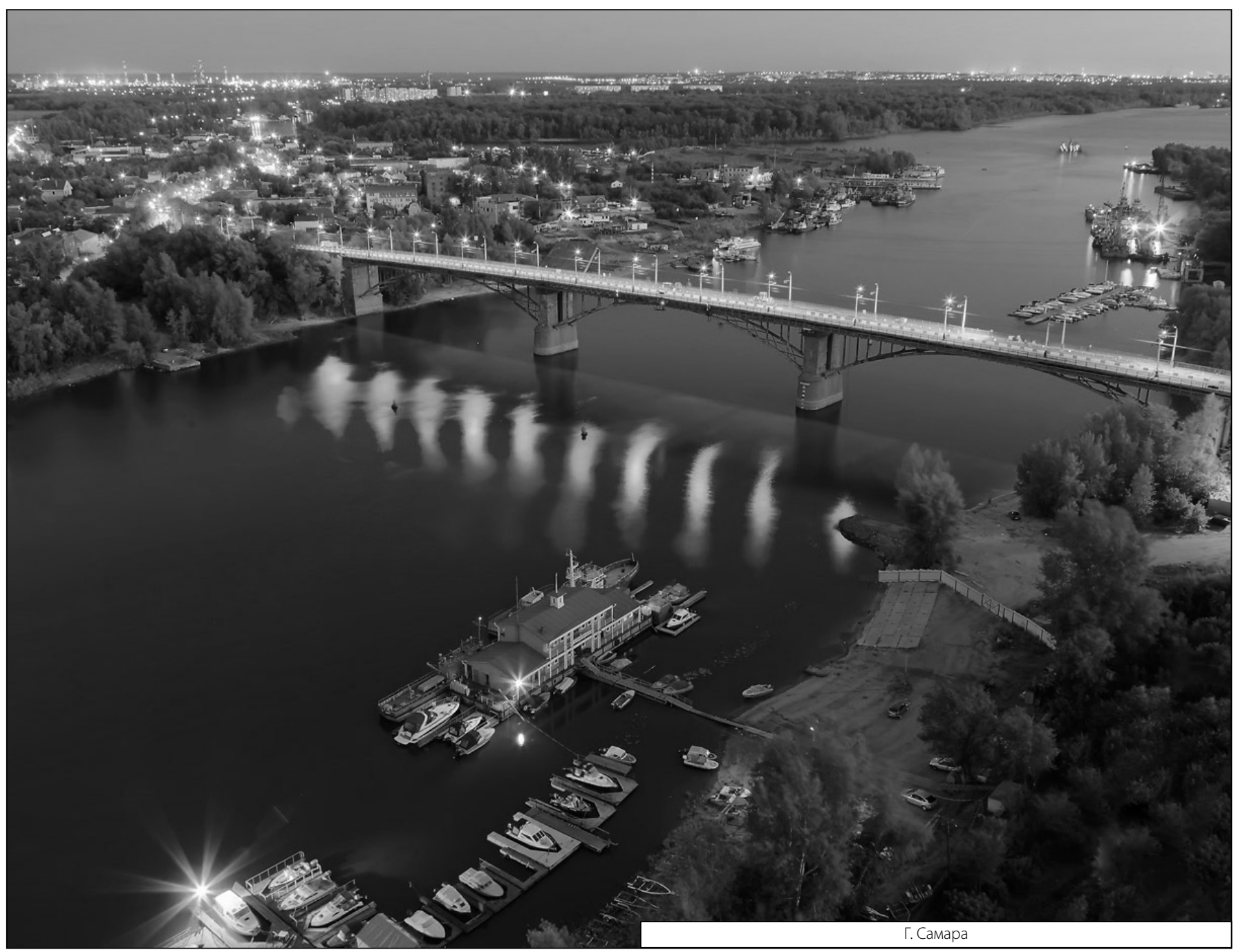

